\title{
Article \\ Improvement of the Standard Chimney Electrostatic Precipitator by Dividing the Flue Gas Stream into a Larger Number of Pipes
}

\author{
Juraj Trnka ${ }^{1, *}$, Jozef Jandačka ${ }^{2}$ and Michal Holubčík ${ }^{2}$ (B) \\ 1 Research Center Department, University of Žilina, Univerzitná 8215, 01026 Žilina, Slovakia \\ 2 Department of Power Engineering, University of Žilina, Univerzitná 8215, 01026 Žilina, Slovakia; \\ jozef.jandacka@fstroj.uniza.sk (J.J.); michal.holubcik@fstroj.uniza.sk (M.H.) \\ * Correspondence: trnka2@uniza.sk; Tel.: +42-195-055-4824
}

Citation: Trnka, J.; Jandačka, J.; Holubčík, M. Improvement of the Standard Chimney Electrostatic Precipitator by Dividing the Flue Gas Stream into a Larger Number of Pipes. Appl. Sci. 2022, 12, 2659. https://doi.org/10.3390/app12052659

Academic Editors: Artur Badyda and Chris G. Tzanis

Received: 21 January 2022

Accepted: 2 March 2022

Published: 4 March 2022

Publisher's Note: MDPI stays neutral with regard to jurisdictional claims in published maps and institutional affiliations.

Copyright: (C) 2022 by the authors. Licensee MDPI, Basel, Switzerland. This article is an open access article distributed under the terms and conditions of the Creative Commons Attribution (CC BY) license (https:// creativecommons.org/licenses/by/ $4.0 /)$.

\begin{abstract}
Combustion of biomass-based solid fuels is becoming increasingly popular, especially in small heat sources. A major problem in the combustion of biomass is the increased production of emissions and especially the solid component of PM particles. Currently, the most used solution to this problem is the application of electrostatic chimney separators, which innovations are discussed in our article. Two models of electrostatic precipitators were constructed in this work. The aim of this work was to compare the use of a standard single-pipe chimney electrostatic precipitator with a newer four-pipe variant. Eight measurements were performed on both devices with and without the use of an electrostatic precipitator, on the basis of which the separation efficiency was evaluated for both variants. The results of the measurements showed the initial value of the average PM production in the one-pipe variant decreased from 1012 to $416 \mathrm{mg} \cdot \mathrm{m}^{-3}$ when using the separator, while in the use of the four-pipe variant it decreased from the starting value 342 to only $152 \mathrm{mg} \cdot \mathrm{m}^{-3}$. These results show that the improvement of the classic single-pipe separator by increasing the number of tubes significantly reduced the production of PM emissions and increased the separation efficiency from 66 to $85 \%$.
\end{abstract}

Keywords: electrostatic precipitator; particulate matter; emissions reduction

\section{Introduction}

Particulate matter emissions released into the environment from thermal decomposition of fuel because of human activity are currently one of the most serious environmental burdens. PM particles from combustion, reaching a size of only a few micrometers, are easily carried into the environment together with the flue gases, where they can be inhaled by living organisms with risks of development of lung diseases [1].

The main source of PM emissions is the combustion of solid fuels in small heat sources, the number of which is constantly growing. This trend is also increased by the promotion of biomass as a renewable resource, which is becoming the preferred alternative to cleaner but more expensive fossil natural gas. In addition to promoting green energy from biomass, the European Union's policy also aims to reduce emissions from combustion devices that are constantly innovated to reach new standards. This effort of design modifications on the combustion devices significantly reduces their emissivity while guaranteeing optimal combustion conditions. Evidence of this is one Chinese research report that shows a 76\% reduction in PM emissions by design improvements to traditional coal stoves. There was a reduction of up to $95 \%$ while using a modern gasification boiler [2]. Further research has shown a significant reduction in emissions by ensuring optimal combustion conditions using separation baffles and combustion air distribution [3].

However, these design modifications in combustion devices reach the limits of technical possibilities and it is therefore necessary to focus on technologies of secondary separation of already formed particles by using mechanical, electrostatic, or filtration separators as 
it is in large heat sources. Initial research was focused on the use of mechanical chamber separators using centrifugal, gravitational, or inertial force to reduce the velocity of the carried particle below the rate of fall $[4,5]$.

One study examined the use of a chamber separator with adjustable separation blades. By rotating the blades, it was possible to influence the magnitude of the forces affecting the velocity of the particle. Measurements showed that the largest particles did not pass through the first blade section. Of the total number of particles, $55.17 \%$ were captured. However, despite the entrapment of larger particles, smaller particles escaped in the flue gas stream [6].

Despite the widespread use of mechanical separators, the main part of research is currently focused on the use of electrostatic precipitators, which are preferred due to their simple installation with low space requirements, high efficiency, and low cost. The wider use of electrostatic precipitators has been facilitated by the reduction in the cost of manufacturing high-voltage transformers, which are among the more expensive components of the separator. The separation effect is achieved by creating a high voltage potential between the positive and negative electrodes between which the entrained flue particles pass. The particles are charged by ion current from the discharge electrode and are attracted to collection grounded electrode. Most electrostatic precipitators use chimney pipes directly as collection electrodes, with a charging wire electrode stretched in the middle. Much research has already been applied to conventional chimney electrostatic precipitators and some models are currently available on the market [7-11].

Most research confirms the low efficiency of standard chimney separators and therefore some focus on their design improvement is necessary to increase the efficiency of particle separation [12-15].

From a survey of the conducted research, the most inspiring models for us were multiple tubular separators, such as the Thai model, which achieved an efficiency of up to $70 \%$ [16-18].

The aim of this work was to continue this research and build an improved model of the standard chimney separator by multiplying the number of pipes. Our goal was to develop a multiple-tubular precipitator that would perform the function of a standard chimney with the highest possible efficiency with low space requirements and preservation of esthetics. Increasing the number of tubes in standard chimney pipe resulted in an increase in the separation area and a reduction in the long distance between the electrodes, which led to an increase in efficiency.

\section{Materials and Methods}

\subsection{Experimental Combustion Device}

In this work, a combustion device with a suitable chimney shape was used to which the electrodes of the electrostatic precipitator were connected. For the purposes of the experiment, a Venus 850 fireplace insert with a nominal power of 7.4 KW and an efficiency of $80.5 \%$ was used for measurements. Beech wood with a bark and calorific value of $16.8 \mathrm{MJ} / \mathrm{kg}$ was used as fuel. The measurements were performed during the nominal power of the fireplace at a load of approximately $2.7 \mathrm{~kg}$ of wood per $30 \mathrm{~min}$ measurement. During the measurement, the basic parameters of the combustion process, such as the chimney temperature and the chimney draught at the level of $12 \pm 2 \mathrm{~Pa}$, were recorded and maintained under standardized conditions by means of a measuring control panel. PM emissions were measured gravimetrically, each time $5 \mathrm{~min}$ after loading, until the flame and chimney draught stabilized. Initially, it was necessary to create a continuous layer of embers, followed by other phases of combustion such as loading, burning of volatile combustibles, and solid carbon burnout. The whole process was repeated for each measurement, as shown in Figure 1. 


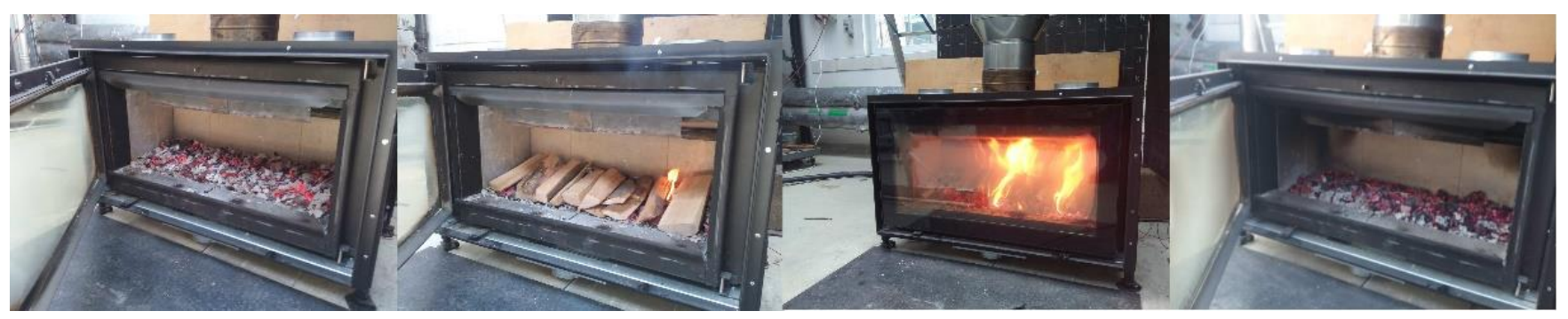

Figure 1. The course of the phases of the combustion process during measurement.

\subsection{Model of Electrostatic Precipitator with HV Power Supply}

Chimney electrostatic precipitators were connected directly beyond the combustion device on chimney pipe. The first classical model of the separator shown in Figure $2 \mathrm{a}$ consisted of a $2 \mathrm{~m}$ standard chimney pipe with a diameter of $200 \mathrm{~mm}$, in the middle of which was a charging electrode in the form of a copper wire stretched by a weight. The positive electrode was separated from the negative electrode by a $200 \mathrm{~mm}$ ceramic fireclay chimney through which a supporting threaded rod for the negative electrode was passed.

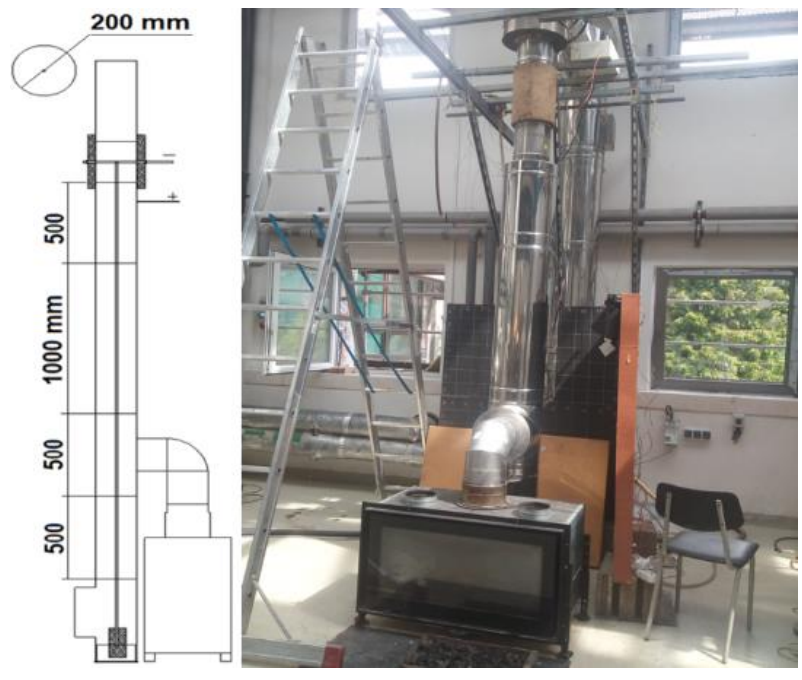

(a)
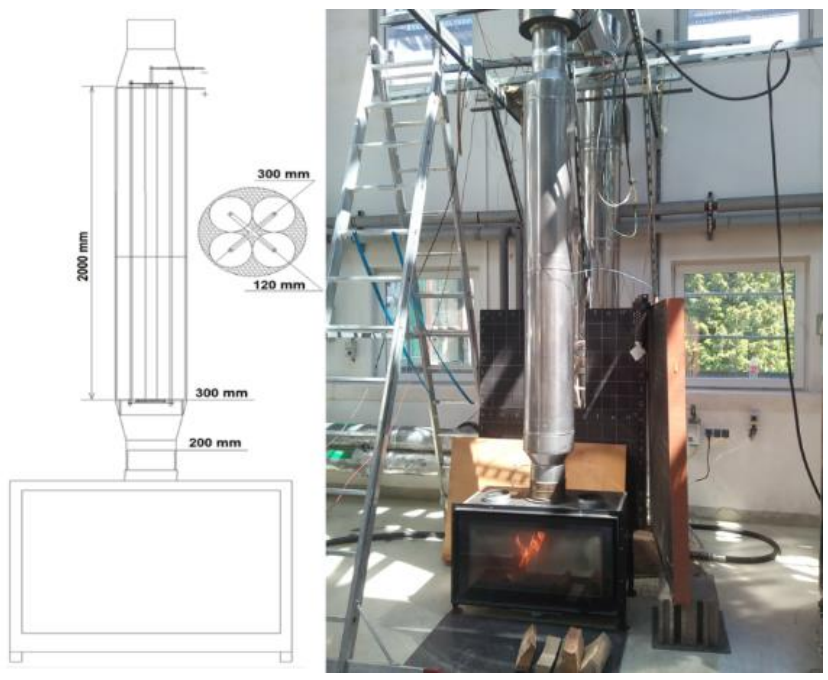

(b)

Figure 2. Experimental setup: (a) combustion device with standardized chimney electrostatic precipitator; (b) improved four-pipe chimney electrostatic precipitator.

The second model, shown in Figure $2 \mathrm{~b}$, consisted of a $2 \mathrm{~m}$ chimney pipe with a diameter of $300 \mathrm{~mm}$ in the center of which were four $120 \mathrm{~mm}$ pipes through the center of which passed four charging electrodes. The charging electrodes were formed of rigid threaded rods, which were firmly connected at the top and bottom by crosses of iron strips.

Both models of the electrostatic precipitator were connected to their own high voltage (HV) power supply with input voltage $220 \mathrm{~V}$ connected to the public network. For the first standard model of a chimney electrostatic precipitator, a CX-600A high-voltage power supply with an electrode spacing of up to $10 \mathrm{~cm}$ was used. The power supply had a maximum power of $300 \mathrm{~W}$ with adjustable high voltage parameters from 5 to $60 \mathrm{kV}$.

For a smaller electrode distance of up to $6 \mathrm{~mm}$, the second improved model required a power supply with only $100 \mathrm{~W}$ and adjustable high voltage parameters from 10 to $20 \mathrm{kV}$. Therefore, we could use the lower-cost model CX-120A. Both sources shown in Figure 3 were released at full power during the measurements, and had built-in safety features against damage and skipping of the short circuit electrostatic arc between the electrodes. 


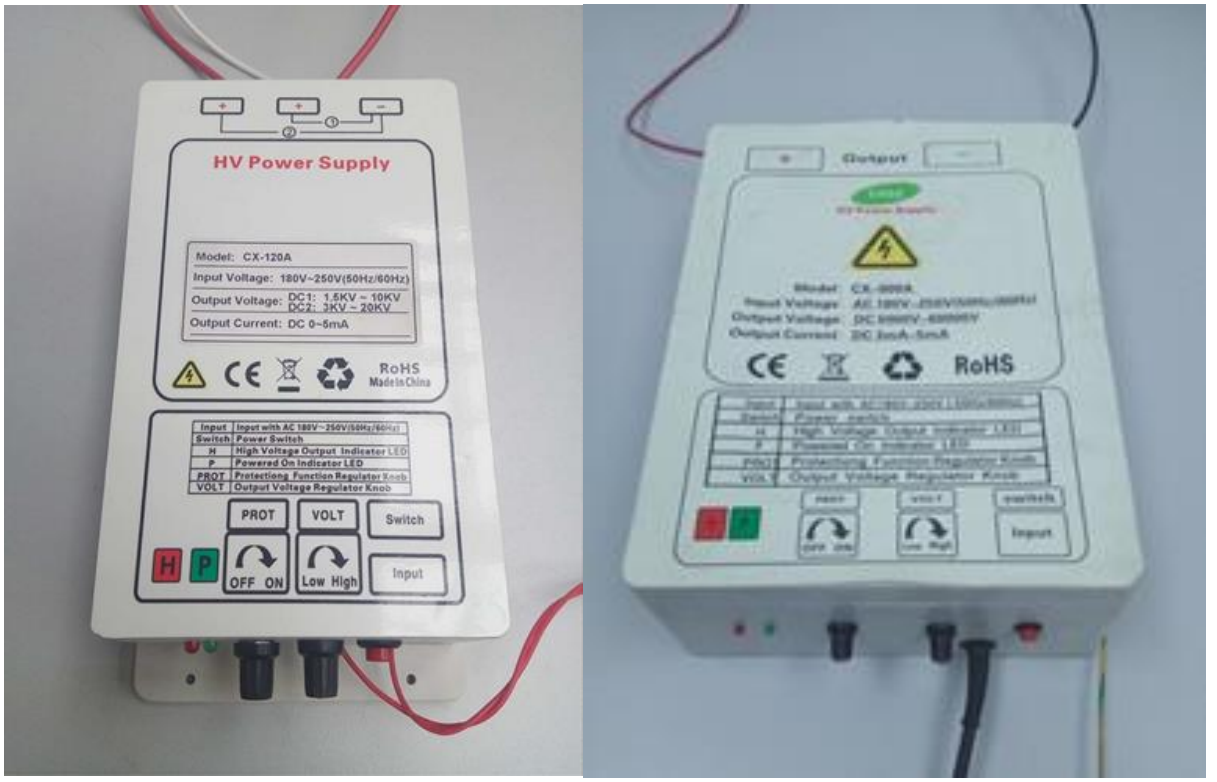

(a)

(b)

Figure 3. Experimental HV power supply: (a) model CX-120A with power $100 \mathrm{~W}$ and voltage $20 \mathrm{kV}$; (b) model CX-600A with power and $300 \mathrm{~W}$ and voltage $60 \mathrm{kV}$.

\subsection{Graviometric Method for Measuring PM Emissions}

The basic quantity measured during all measurements was the value of PM emissions produced, which we determined using the gravimetric method. The measurement consists of taking a representative sample with a cascade cylindrical impactor from the flue gas in the flow rate measurement section, which lies directly behind the electrostatic precipitator. The impactor consists of a suction nozzle and a three-chamber space, where the flue gas flow rate is directed by conical inserts to a set of three sampling filters composed of glass fibers. The three-filter probe allows for simultaneous measurement of all three particle sizes: $P M>10$, PM 10-2.5, and PM < 2.5. Along with the particle separation, the basic parameters such as chimney draft and temperature required for further calculations are also measured using the ANHOLM measuring control panel during the combustion process. It is also necessary to measure the velocity to ensure an isokinetic condition, which is determined by the same sampling rate as the flue gas flow rate in the chimney. The measuring probes that were used are shown in Figure 4.
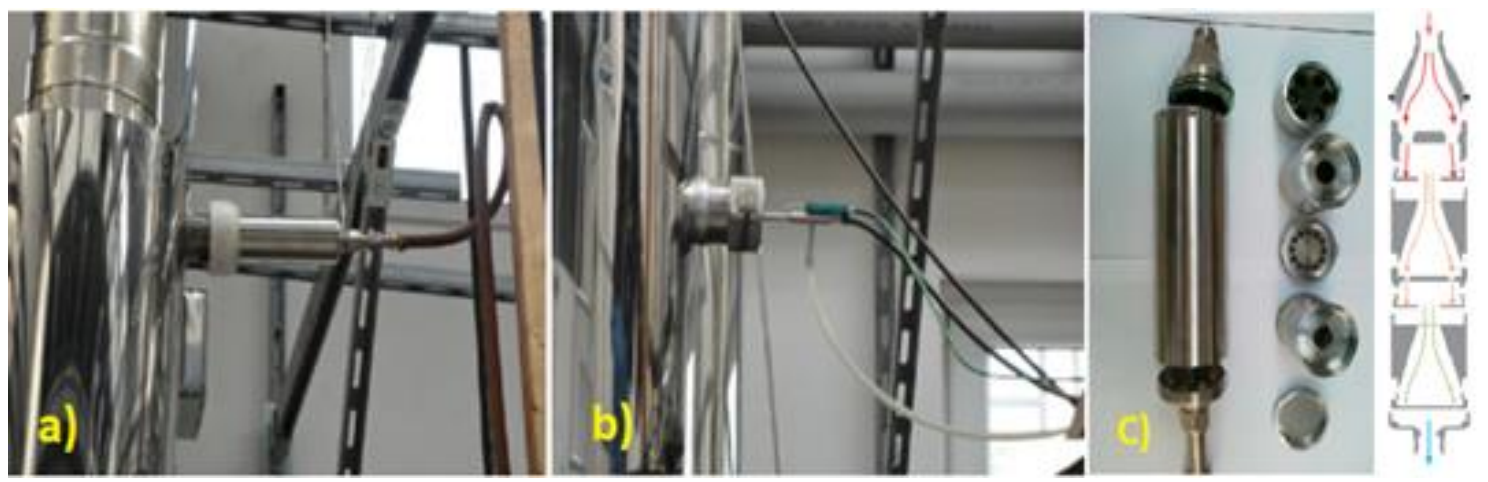

Figure 4. Measuring probes: (a) probe for measuring PM production; (b) probe for measuring chimney temperature and flow rate; (c) layout of cascade sampling probe parts.

Measurements were performed using a TCR Tecora Isostack Basic device, which consists of probes for measuring chimney draught and temperature, and a sampling probe with filter columns for capturing PM from flue gases. The flue gases were then cooled 
in a cooling and condensing unit and dried in a drying tower containing silica gel. The measurement itself consists of several basic steps. After setting the basic measurement parameters on the TCR Tecora Isostack Basic analyzer, it is necessary to prepare a set of collection filters. The filters must be dried and weighed dry. A Radwag WPS 50X drying balance was used for drying. Prior to each measurement, the impactor must be thoroughly cleaned of settled impurities and heated to operating temperature to prevent condensation in the impactor cylinder. After a 30 min sampling of the particles, the measuring device notified us of the end of the measurement by writing out the evaluation tape with the basic measurement parameters, which are necessary for further calculation of the PM concentration in the flue gas. The filters must be dried again and weighed after the measurement. From the difference in the weight of the filters before and after the measurement, we determined the mass of collected particles. To calculate the final concentration of PM in the gas, it is necessary to insert the mass of particles together with the data from the output tape into the following relation [19]:

$$
C=\frac{\left(m_{2}-m_{1}\right)}{V_{g n}} \cdot 1000
$$

where $C$ is the concentration converted to normal conditions in dry gas $\left(\mathrm{mg} \cdot \mathrm{m}^{-3}\right), V_{g n}$ is flue gas sample volume $\left(\mathrm{m}^{3}\right), m_{2}$ is weight of filter after measurement $(\mathrm{g})$, and $m_{1}$ is weight of filter before measurement $(\mathrm{g})$.

From the value of the concentration of PM particles in the flue gas under standardized conditions $C$, it is also possible to calculate the value of the concentration under reference conditions according to the legal regulation $C^{r}$, which is defined by the relation:

$$
C^{r}=\frac{20.95-O_{2}^{r e f}}{20.95-O_{2}^{\text {priem }}}
$$

where $C^{r}$ is concentration for reference conditions according to the legislative regulation $\left(\mathrm{mg} . \mathrm{m}^{-3}\right), \mathrm{O}_{2}^{\text {priem }}$ is measured average oxygen content in the gas volume $(\%)$, and $\mathrm{O}_{2}^{\text {ref }}$ is reference oxygen content $(\%)$.

\section{Results}

\subsection{Analysis of Measurements Results}

During the measurements, the basic quantities influencing the separation process were recorded, as shown in Table 1 . The average values of the measured quantities mainly indicate the electricity consumption and the efficiency of the combustion process. This can be attributed to the larger cross-sectional area of the chimney, which resulted in a slight reduction in the flue gas flow rate and in the chimney draft. Closer electrode spacing also reduced the level of high voltage required to achieve the sufficient corona effect, which led to a reduction in energy consumption.

Table 1. Average value of basic measured parameters of the precipitation process.

\begin{tabular}{cccccc}
\hline ESP $^{1}$ & Temperature & Draft & Current & Voltage & Power \\
\hline One pipe & $256 \pm 3^{\circ} \mathrm{C}$ & $12.9 \pm 0.7 \mathrm{~Pa}$ & $0.8 \pm 0.1 \mathrm{~mA}$ & $60 \pm 0.2 \mathrm{kV}$ & $50 \pm 2 \mathrm{~W}$ \\
Four pipes & $240 \pm 3{ }^{\circ} \mathrm{C}$ & $12.2 \pm 0.7 \mathrm{~Pa}$ & $1.2 \pm 0.1 \mathrm{~mA}$ & $20 \pm 0.2 \mathrm{kV}$ & $25 \pm 2 \mathrm{~W}$ \\
\hline
\end{tabular}

${ }^{1}$ Electrostatic precipitator model.

The gravimetric method of measuring the mass of particles during the measurements helped us to determine the efficiency of the collection process. During the experiments, eight measurements of PM emission production were performed on both models of separators. For each model, four measurements were made with the separator on and four with the separator off. The results of the measurements were samples of PM particles deposited on the collection filters from which we could obtain not only the mass of the particles but also visually evaluate the combustion process from an emission point of view. The individual sets of collection filters for each measurement are shown in Figure 5. 


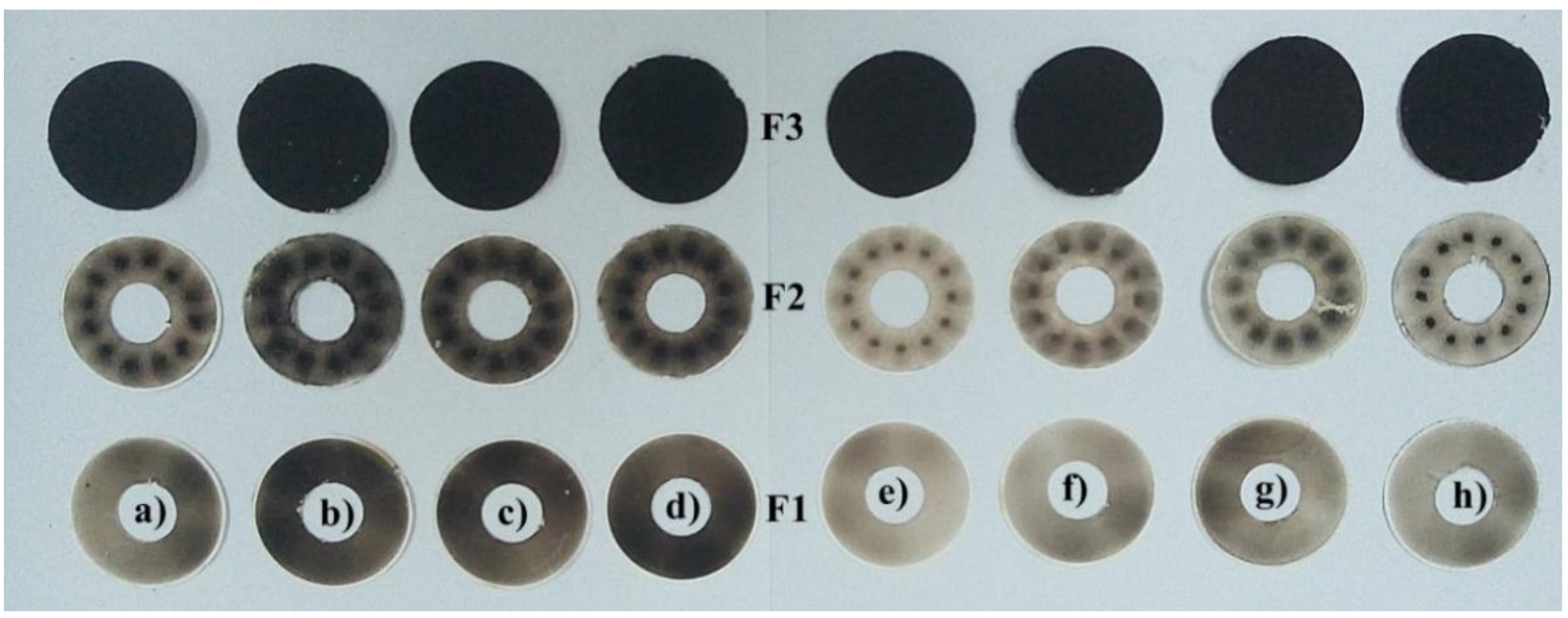

Figure 5. Sets of collection filters F1 PM > 10, F2 PM 10-2.5, and F3 PM $<2.5$ for individual measurements of variant 1: (a) M1, (b) M2, (c) M3, (d) M4, (e) M5, (f) M6, (g) M7, and (h) M8.

Based on the color of the filters capturing larger particles, with increasing time the chimney becomes clogged and the emissions gradually increase to a point when an electrostatic precipitator was used, which slowed this process slightly. From the masses of the particles deposited on the filters, a much more accurate value of emissions was calculated and given in milligrams per cubic meter; the results are shown graphically in Figure 6.

Figure 6. Amount of PM emissions for measurements of variant 1.

These results show that using a standard chimney electrostatic precipitator was able to reduce the average value of PM emissions from 1011.81 to $342.03 \mathrm{mg} . \mathrm{m}^{-3}$, which represents a separation efficiency of $66.2 \%$. Upon closer examination of the results, we notice a remarkable tendency of increasing efficiency together with decreasing particle size. In the largest PM 10 fraction, it was only $10.2 \%$, in the case of particles with the PM 10-2.5 fraction, it had already increased to $27.5 \%$, and in the smallest particles the $\mathrm{PM}<2.5$ fraction had already jumped up to $68.42 \%$. The results obtained from first measurements are satisfactory for a standard chimney separator, but despite the relatively high efficiency, we can see relatively high initial values of PM emissions. However, by using the new four-pipe model, we can see a significant decrease in the input value of PM emissions, which was further reduced by using the electrostatic precipitating effect, as shown in Figure 7. 


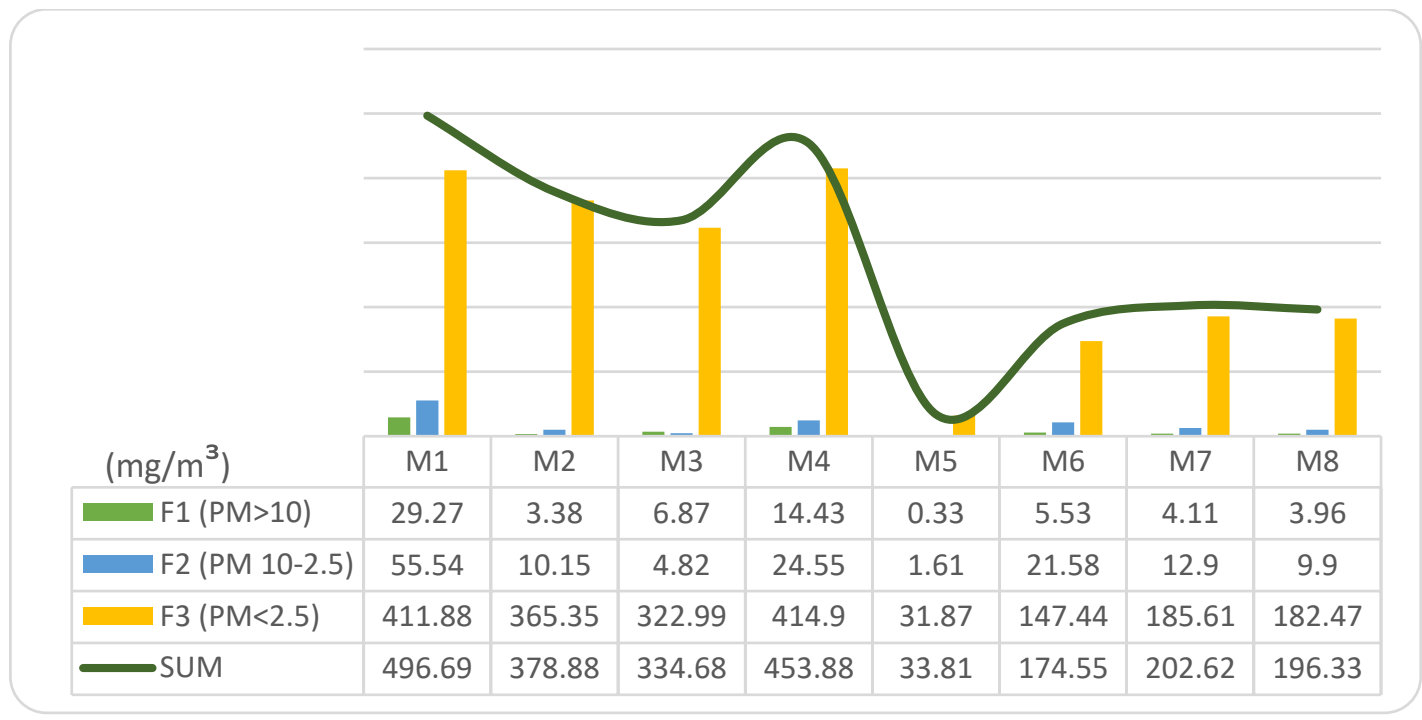

Figure 7. Amount of PM emissions in measurements of variant 2.

The results of the measurements when using the improved separator show the average reduction of PM emissions from 416.03 to $152.83 \mathrm{mg} . \mathrm{m}^{-3}$, at an efficiency of $63.5 \%$. More detailed results in this case show good results for separation of larger particles while maintaining the separation efficiency of smaller particles, namely $74.2 \%$ for PM 10 and $48.4 \%$ for PM 10-2.5, and $63.9 \%$ for PM $<2.5$. Compared to the first model, the average separation efficiency value was lower but considering the passive separation of the technical design of the new model itself, we can see a significant reduction in emissions. Considering the initial value of $1011.81 \mathrm{mg} \cdot \mathrm{m}^{-3} \mathrm{PM}$ emissions, the introduction of the newer model decreased the value to $152.83 \mathrm{mg} \cdot \mathrm{m}^{-3}$, which represents an increase in overall efficiency of up to $85 \%$.

In addition to graphical data, we can also evaluate the combustion process using collection filters and observe the same tendency to increase emissions from clogging of the separation surfaces. However, occasional anomalies in the color of the filters may also be due to the higher bark content in the individual measurements. The individual measuring filters are again shown in Figure 8.

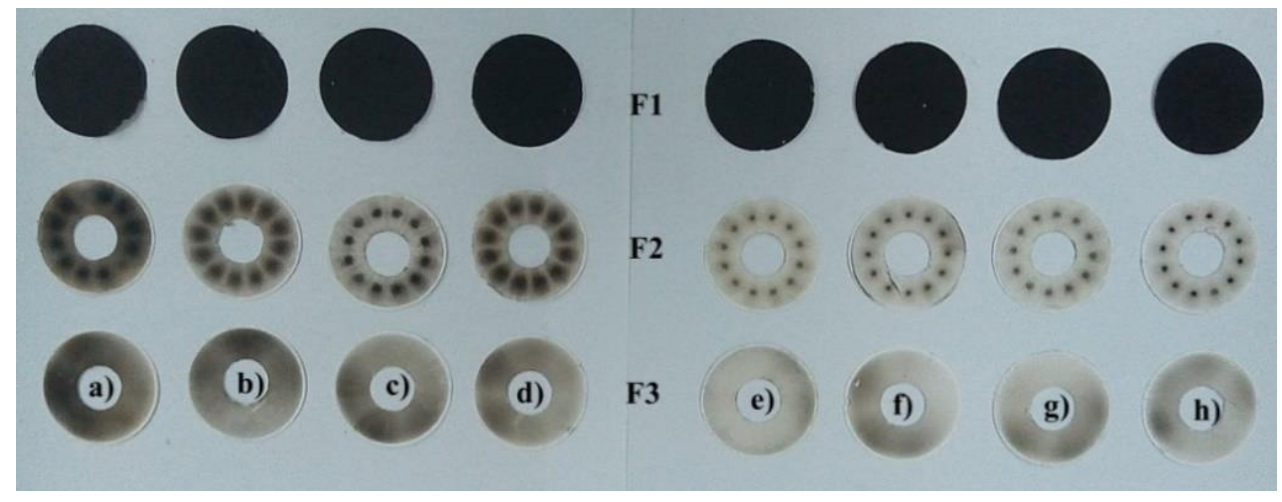

Figure 8. Sets of collection filters F1 PM > 10, F2 PM 10-2.5, and F3 < 2.5 for individual measurements of variant 2: (a) M1, (b) M2, (c) M3, (d) M4, (e) M5, (f) M6, (g) M7, and (h) M8.

\subsection{The Analysis of Detected Dependencies}

These results show that the reduction of PM emissions by using the new four-pipe separator model was mainly due to the increasing number of pipes and decreasing pipe diameter. This led to better containment of particles by the collection surface [20,21], which is also confirmed by the mathematical model results shown in Figure 9. 


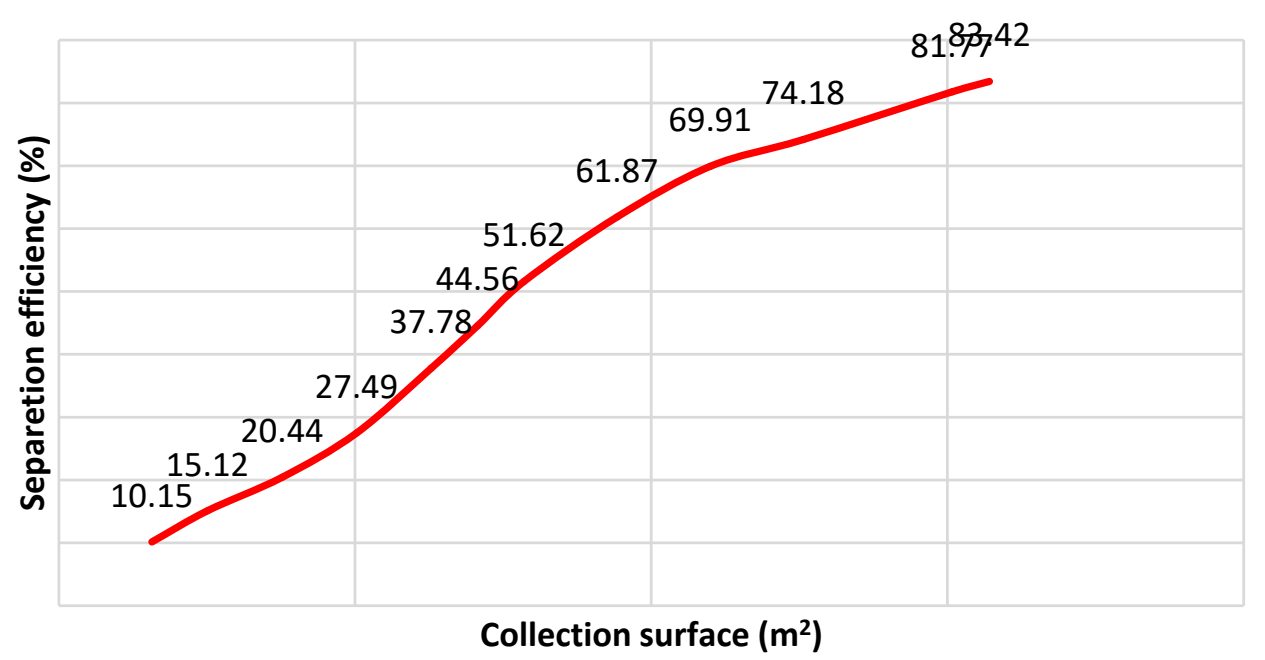

Figure 9. Graphical dependence of separation efficiency on the size of the collection surface.

The standard stainless-steel chimney with a diameter of $200 \mathrm{~mm}$ and collection surface of $0.628 \mathrm{~m}^{2}$ per meter compared to the new improved model with four $120 \mathrm{~mm}$ pipes with a collection surface of $1.508 \mathrm{~m}^{2}$ represents almost 2.4 times magnification. The distribution of the flue gas stream into smaller pipes also leads to a more efficient and stable effect of the electrostatic field on the particle [22,23], which is also confirmed by the mathematical model results shown in Figure 10.

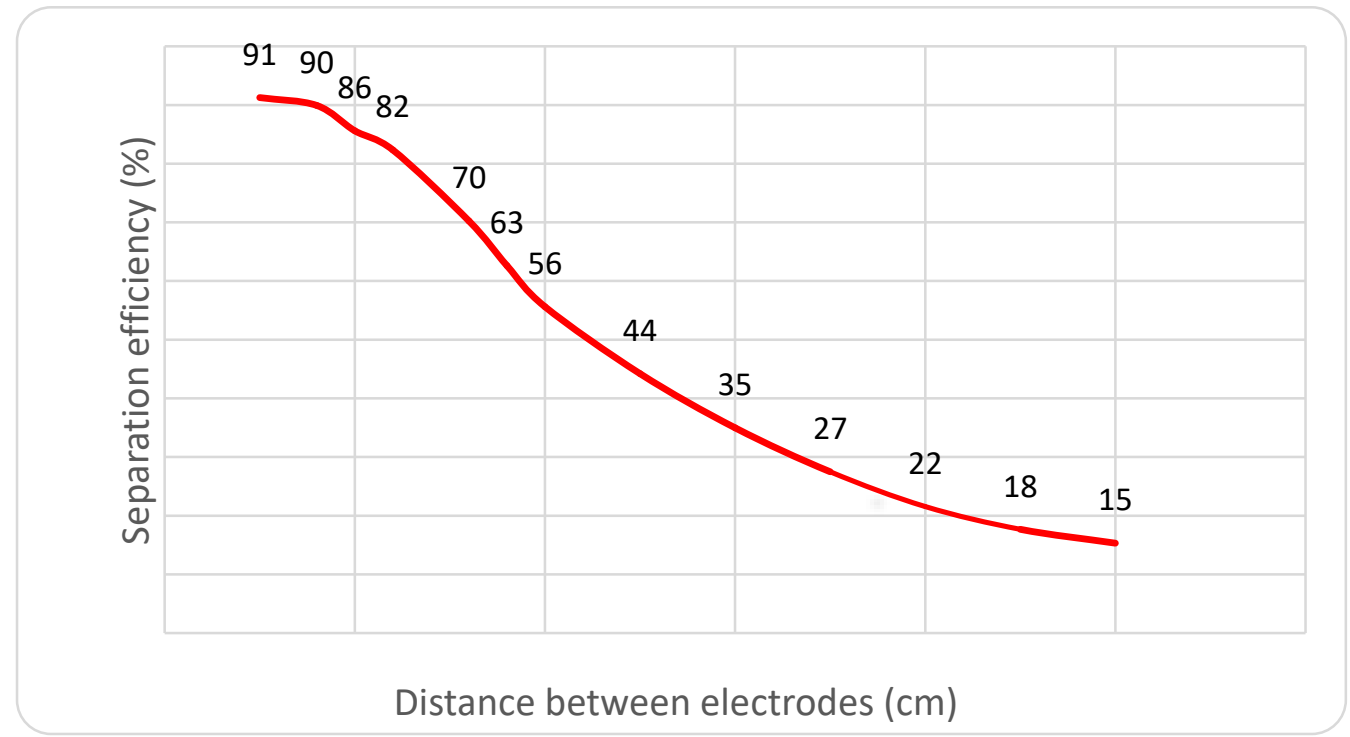

Figure 10. Graphical dependence of separation efficiency on the distance between electrodes.

Smaller pipe diameters allow the use of lower high voltage, which allows the use of smaller and less expensive high voltage sources with reduced energy consumption. This was also proved by our measurements in which the first stronger source during operation at a voltage level of $60 \mathrm{kV}$ consumed approximately $50 \mathrm{~W}$ during the measurements. The weaker model at a voltage level of $20 \mathrm{kV}$ consumed only $25 \mathrm{~W}$. At the same time, redistributing the flue gas flow into a larger number of pipes further increased the crosssectional area from $0.0314 \mathrm{~m}^{2}$ to $0.0452 \mathrm{~m}^{2}$, which further reduced the particle velocity rate. The turbulent flow caused by changing the cross-section of the pipe also helped to slow the velocity of the flowing particles [24]. 


\section{Discussion and Conclusions}

The issue of reducing PM emissions by using electrostatic precipitators in small heat sources is currently one promising area of research. The first prototypes of commercially available chimney electrostatic precipitators are slowly beginning to appear on the market. Despite their simple construction and low construction costs, these devices do not achieve sufficient efficiencies. The solution to this problem is to improve the chimney separators with elements from the industrial practice of large heat sources [25-28].

This work focused on improving the separation efficiency of a standard chimney separator by increasing the number of pipes. During the work, eight measurements of PM emissions were performed on a conventional chimney separator and eight on its improved four-pipe version. Four measurements with and without electrostatic precipitator were performed for each model. The results of the measurements showed a reduction of PM emissions from an initial value of $1011.81 \mathrm{mg} \cdot \mathrm{m}^{-3}$ to a final value of $152.83 \mathrm{mg} \cdot \mathrm{m}^{-3}$, which represents separation efficiency at $85 \%$. We achieved this reduction by improving the effect of electrostatic precipitation processes and by improving the precipitation ability of the chimney precipitator itself. The measurements confirmed that the increase in separation efficiency was achieved by reducing the distance between the electrodes and by increasing the collection surface and cross-section of the chimney. Because of the increase in the number of pipes, the collection area increased 2.4 times and the cross-sectional area increased by $30 \%$, which led to slowing the flue gas flow rate. From the electrostatic point of view, we also managed to achieve 50\% energy savings by reducing the high voltage of the electrostatic field.

The use of electrostatic precipitators to reduce PM emissions is shown to be effective. Improving the standard chimney model by increasing the number of pipes brings significant benefits to the issue; combined with further measurements, reduction of PM emissions can be explored further by adding pipes to create a more compact and efficient model.

Author Contributions: Conceptualization, J.T.; Data curation, J.T.; Formal analysis, J.J. and M.H.; Funding acquisition, J.J. and M.H.; Investigation, J.T. and M.H.; Resources, J.T. All authors have read and agreed to the published version of the manuscript.

Funding: This research was funded by the Integrated Infrastructure Operational Program for the project: Creation of a Digital Biobank to support the systemic public research infra-structure, ITMS: 313011AFG4, co-financed by the European Regional Development Fund; VEGA 1/0233/19 “Structural modification of a burner for the combustion of solid fuels in small heat sources" and VEGA $1 / 0479 / 19$ "Influence of combustion conditions on the production of solid pollutants in small heat sources".

Institutional Review Board Statement: Not applicable.

Informed Consent Statement: Not applicable.

Data Availability Statement: Not applicable.

Conflicts of Interest: The authors declare no conflict of interest.

\section{References}

1. Kelz, J.; Brunner, T.; Obernberger, I.; Jalava, P.; Hirvonen, M. PM Emissions from Old and Modern Biomass Combustion Systems and Their Health Effects. In Proceedings of the 18th European Biomass Conference, Lyon, France, 3-7 May 2010 ; pp. 1-13.

2. Shen, G. Changes from traditional solid fuels to clean household energies-Opportunities in emission reduction of primary PM2,5 from residual cook stoves in China. Biomass Bioenergy 2016, 86, 28-35. [CrossRef]

3. Čajova, K.N.; Čaja, A.; Patsch, M.; Holubčík, M.; Durčanský, P. Dependance of the Flue Gas Flow on the Setting of the Separation Baffle in the Flue Gas Tract. Appl. Sci. 2021, 11, 2961. [CrossRef]

4. Sulovcova, K.; Nosek, R.; Jandačka, J.; Michal, H. Geometrical Optimization of the Flue Gas Path with Regard to the Reduction of Particulate Matter. Emiss. Control Sci. Technol. 2018, 4, 40-44. [CrossRef]

5. Tan, C.Z.; Zhang, Y. Advances in Centrifugal Separators for Particulate Matter Control from Stationary Sources. J. Therm. Sci. 2002, 11, 283-288. [CrossRef]

6. Kantová, N.; Jandačka, J.; Sladek, S.; Holubčik, M.; Čaja, A. The flowing of particulate matter through baffles depending on their number in the flue gas tract. Transp. Res. Procedia 2019, 40, 724-728. [CrossRef] 
7. Schmatloch, V.; Rauch, S. Design and characterization of an electrostatic precipitator for small heating appliances. J. Electrost. 2005, 63, 85-100. [CrossRef]

8. Dastori, K.; Kolhe, M.; Mallard, C.; Makin, B. Electrostatic precipitation in a small scale wood combustion furnace. J. Electrost. 2011, 69, 466-472. [CrossRef]

9. Rodriguez, L.G.J.; Suhonen, H.; Laitinen, A.; Tissari, J.; Kortelainen, M.; Tiitta, P.; Lahde, A.; Keskinen, J.; Jokiniemi, J.; Sippula, O. A novel electrical charging condensing heat exchanger for efficient particle emission reduction in small wood boilers. Renew. Energy 2020, 145, 521-529. [CrossRef]

10. Hartmann, H.; Turowski, P.; Kiener, S. Electrostatic precipitators for small-scale wood combustion systems-Results from laband field tests. In Proceedings of the Central European Biomass Conference (CEBC), Graz, Austria, 26-28 January 2011; pp. 1-30.

11. Drga, J.; Kubas, Š.; Martvoňová, L. Numerical model expressing the amount of capture of particulate matter by an electrostatic precipitator for small heat sources. Adv. Therm. Process. Energy Transform. 2020, 3, 81-85.

12. Bolga, A.; Paur, R.H.; Woletz, K. Development and Study of an Electrostatic Precipitator for small Scale Wood Combustion. Int. J. Plasma Environ. Sci. Technol. 2011, 5, 168-173.

13. Wen, T.Y.; Wang, H.; Krichtafovitch, I.; Mamishev, V.A. Novel electrodes of an electrostatic precipitator for air filtration. J. Electrost. 2015, 73, 117-124. [CrossRef]

14. Kim, J.H.; Yoo, H.J.; Hawang, S.Y.; Kim, G.H. Removal of Particulate Matter in a Tubular Wet Electrostatic Precipitator Using a Water Collection Electrode. Sci. World J. 2012, 2012, 532354. [CrossRef]

15. Jaworek, A.; Krupa, A.; Czech, T. Modern electrostatic devices and methods for exhaust gas cleaning: A brief review. J. Electrost. 2007, 3, 133-155. [CrossRef]

16. Intra, P.; Limueadpahi, P.; Tippayawong, N. Particulate Emission Reduction from Biomass Burning in Small Combustion Systems with a Multiple Tubular Electrostatic Precipitator. Part. Sci. Technol. J. 2010, 28, 547-565. [CrossRef]

17. Jaworek, A.; Sobczyk, A.T.; Marchewicz, A.; Czech, T. Particulate matter emission control from small residential boilers after biomass combustion. A review. Renew. Sustain. Energy Rev. 2021, 137, 110446. [CrossRef]

18. Berhardt, A.; Lezsovits, F.; Groß, B. Integrated Electrostatic Precipitator for Small-Scaled Biomass Boilers. Chem. Eng. Technol. 2016, 40, 2. [CrossRef]

19. Nosek, R.; Holubčík, M.; Papučík, Š. Emission Controls Using Different Temperature of Combustion Air. Sci. World J. 2014, 2014, 487549. [CrossRef]

20. Jedrusik, B.; Swierczok, A.; Teisseyre, R. Experimental study of fly ash precipitation in a model electrostatic precipitator with discharge electrodes of different design. Powder Technol. 2003, 135, 295-301. [CrossRef]

21. Chang, L.C.; Bai, H. Effects of Some Geometric Parameters on the Electrostatic Precipitator Efficiency at Different Operation Indexes. Aerosol Sci. Technol. 2020, 33, 228-238. [CrossRef]

22. Yang, Z.; Zheng, C.; Liu, S.; Guo, Y.; Liang, C.; Zhang, X.; Zhang, Y.; Gao, X. Insights into the role of particle space charge effects in particle precipitation processes in electrostatic precipitator. Powder Technol. 2018, 339, 606-614. [CrossRef]

23. Kasdi, A. Computation and measurement of corona current density and V-I characteristics in wires-to-plates electrostatic precipitator. J. Electrost. 2016, 81, 1-8. [CrossRef]

24. Podliński, J.; Dekowski, J.; Mizeraczyk, J.; Brocilo, D.; Chang, S.J. Electrohydrodynamic gas flow in a positive polarity wire-plate electrostatic precipitator and the related dust particle collection efficiency. J. Electrost. 2006, 64, 259-262. [CrossRef]

25. Kumar, A.; Parihar, S.; Hammer, T.; Sridhar, G. Development and testing of tube type wet ESP for the removal of particulate matter and tar from producer gas. Renew. Energy 2015, 74, 875-883. [CrossRef]

26. Yang, Z.; Zheng, C.; Liu, S.; Guo, Y.; Liang, C.; Wang, Y.; Hu, D.; Gao, X. A combined wet electrostatic precipitator for efficiently eliminating fine particle penetration. Fuel Process. Technol. 2018, 180, 122-129. [CrossRef]

27. Peukert, W.; Wadenpohl, C. Industrial separation of fine particles with difficult dust properties. Powder Technol. 2001, 118, 136-148. [CrossRef]

28. Bayless, J.D.; Alam, M.K.; Radcliff, R.; Caine, J. Membrane-based wet electrostatic precipitation. Fuel Process. Technol. 2004, 85, 781-798. [CrossRef] 